\title{
Dinâmica do mercado mundial de papel entre 1961 e 2010
}

\author{
The world market of paper dynamic between 1961 and 2010
}

\author{
D. F. Ribeiro Neto ${ }^{1}$; T. S. Soares ${ }^{1 *}$ \\ ${ }^{1}$ Universidade Federal de Goiás - Regional Jataí, CEP 75801-615 - Jataí, GO, Brasil. \\ *email do autorcorrespondente: thelmasoares@ufg.br
}

(Recebido em 29 de setembro de 2015; aceito em 30 de março de 2016)

\begin{abstract}
Este estudo teve por objetivo caracterizar o mercado mundial de papel e analisar a tendência da produção e a relação risco/retorno das importações e exportações no período de 1961 a 2010. Foram empregados dados anuais de produção, importação e exportação de papel disponibilizados pela Food and Agriculture Organization of the United Nations (FAO) os quais foram agrupados em décadas, perfazendo as cinco décadas referente ao período analisado. A caracterização do setor foi realizada por meio da análise da participação percentual de cada continente, em cada década analisada, na produção de papel e a tendência de crescimento da produção por meio da taxa geométrica de crescimento (TGC). Para a obtenção da relação risco/retorno, admitiu-se a TGC como indicativo de retorno e o coeficiente de variação como indicativo dos riscos. Verificou-se que entre 1961 e 2010, a produção de papel ficou concentrada nos países dos continentes americano e europeu, caracterizando-se pela crescente produção da Ásia e decrescente produção da América. As taxas geométricas de crescimento apresentaram variações entre comportamento crescente e decrescente e sempre com valores positivos, com exceção do continente americano na década de 2000. As importações internacionais de papel apresentaram, com exceção do mercado asiático, uma tendência simétrica para a relação risco/retorno com desempenho similar para as exportações. O comportamento das reações risco/retorno indicaram que o mercado de papel é um investimento atrativo para o capital privado.
\end{abstract}

Palavras-chave: Economia florestal; setor papeleiro; taxa geométrica de crescimento; risco e retorno financeiro.

This study aims to characterize the global paper market and analyze the trend of production and the risk/return ratio of imports and exports in the period 1961 to 2010. Annual data on production, imports and exports of paper were made available by the Food and Agriculture Organization of the United Nations (FAO). The data were grouped in decades, making the five decades for the period analyzed. The characterization of the sector was conducted by analyzing the percentage participation of each continent, in each examined decade, in paper production. The trend of production growth in the decades under a study was evaluated using the rate of geometric growth (RGG). It was considered as indicative of risk the coefficient of variation and as indicative of return the RGG. Between the years of 1961 and 2010, the paper production became concentrated in the Americas and Europe, featuring the ever-increasing production in Asia and a decreasing production in America. The geometric growth rates showed variations between ascending and descending behavior, always with positive values, with the exception of the American continent in the 2000s. The international imports of paper presented, with the exception of the Asian market, a symmetrical trend for the risk/return with similar performance for exports. The behavior of the risk/return responses indicated that the paper market is an attractive investment for private capital.

Keywords: Forestry Economics; paper industry; geometric growth rate; financial risk and return.

\section{INTRODUÇÃO}

O papel pode ser definido como uma camada delgada de elementos fibrosos orientados aleatoriamente e unidos por ligações inter e intrafibras por meio de ligações hidrogênio. É um produto cuja fabricação é uma das práticas mais antigas desenvolvidas pela humanidade e que constitui-se ao mesmo tempo em uma das indústrias tecnologicamente mais desenvolvidas, ocupando lugar de destaque no setor industrial dos países mais desenvolvidos [1].

O papel possui inúmeras variações quanto ao seu tipo e forma de fabricação, cada um com suas características próprias e peculiaridades em sua estrutura, sendo dividido em seis grupos [2]: papéis de embalagem (corrugating materials/wrapping papers), papéis de imprimir e escrever (printing /writing papers), papel de imprensa (newsprint), papéis para fins sanitários (tissue papers), cartões e cartolinas (cartonboard) e papéis especiais. 
O desenvolvimento de uma nação pode ser avaliado por indicadores econômicos e sociais, sendo que, de acordo com Özarslan et al. [3], o consumo per capita de papel e papelão também pode ser considerados como um indicadores de desenvolvimento de um país.

Souza [4] ressalta que aspectos relacionados à urbanização também parecem estar associados ao consumo per capita de papel e papelão.

O consumo mundial de papel é de cerca de 1 milhão de toneladas por dia, sendo o consumo per capita varia por país e região. Atualmente, a média de consumo mundial per capta é de $55 \mathrm{Kg}$, sendo os extremos representados pelos países africanos e pelos Estados Unidos com consumos per capta de $7 \mathrm{Kg}$ e $300 \mathrm{Kg}$, respectivamente [5]. Ressalta-se que os países mais desenvolvidos apresentam um padrão de consumo superior em comparação com os países em desenvolvimento ou subdesenvolvidos, o que explica a diferença de $97,7 \%$ em relação ao consumo de papel dos americanos e dos africanos.

A produção de papel é uma atividade de relevante importância no setor econômico, correspondendo a cerca de $2,5 \%$ da produção industrial do mundo e $2 \%$ do comércio mundial [6], sendo o cenário mundial marcado por intensas competições por mercados e investimentos [7].

Neste contexto, diante da relevância do setor papeleiro para a economia, desenvolveu-se o presente estudo cujo objetivo foi caracterizar o mercado mundial de papel e analisar a tendência da produção e a relação risco/retorno das importações e exportações no período de 1961 a 2010.

\section{MATERIAL E MÉTODOS}

\section{Fonte de dados}

Os dados utilizados foram obtidos na Food and Agriculture Organization of the United Nations [8] e se referem às informações de produção e do comércio bilateral dos continentes que participaram do mercado internacional de papel no período de 1961 a 2010.

Para fins de análise, os dados obtidos foram agrupados em décadas, perfazendo as cinco décadas referente ao período analisado (década de 1960: período de 1961 a 1970; década de 1970: período de 1971 a 1980; década de 1980: período de 1981 a 1990; década de 1990: período de 1991 a 2000 e década de 2000: período de 2001 a 2010).

Não se trabalhou com um período maior porque alguns dados não estavam disponíveis e por entender que o período abrangido é representativo e capta a evolução do mercado mundial de papel.

\section{Caracterização do setor papeleiro e tendência da produção de papel}

A caracterização do setor papeleiro foi realizada por meio da análise da participação percentual de cada continente em cada década analisada. Obteve-se a media da produção na década e a mesmas foram expressas graficamente de forma a evidenciar o comportamento da produção de papel durante o período analisado.

A análise da evolução do mercado internacional de papel no período de 1961 a 2010 foi realizada empregando o método descrito por Gujarati [9] e aplicado por Noce et al. [10], Soares et al . [11] e Gouveia [12] para avaliar, respectivamente, o mercado de aglomerados, borracha natural e amêndoas de babaçu, o qual se baseia na taxa geométrica de crescimento (TGC).

Para calcular a TGC, parte-se do modelo de regressão linear: $Y=a . e^{b T}$, em que: $\mathrm{Y}=$ variável dependente; $\mathrm{T}=$ tempo; $\mathrm{a}$ e $\mathrm{b}=$ parâmetros a serem estimados.

Aplicando a forma logarítmica, tem-se: $\log Y=\log a+T \log b$

Desse modo, a TGC é obtida pela expressão $T G C=($ antlog $b-1) \times 100$

Conforme Noce et al. [1], níveis de significância do parâmetro estimado "b", avaliado pelo teste "t", superiores a 10\%, aumentam a probabilidade de erro em afirmar que a TGC é estatisticamente diferente de zero. Portanto foram considerados somente os valores estimados significantes a $5 \%$.

A partir das informações sobre a produção de papel foi possível analisar (para o mundo e para os continentes as principais mudanças ocorridas nas décadas analisadas. 


\section{Relação risco/retorno das importações e exportações}

Risco e retorno são variáveis básicas da tomada de decisão de investimentos. Genericamente, o risco é uma medida de volatilidade ou incerteza dos retornos e o retorno é a expectativa de receitas de qualquer investimento [13].

O risco pode também ser assumido como a variação do retorno de um ativo financeiro em relação ao seu retorno esperado. Assim, o risco pode ser tratado estatisticamente, por probabilidades, desvio-padrão ou coeficiente de variação enquanto o retorno pode ser medido calculando a variação do preço do ativo no tempo [14].

Neste estudo, a relação risco/retorno foi obtida a partir das séries de valores de importações e exportações (expressas em dólares), para os quais foram calculados a a TGC e o desvio-padrão dos preços. Estes indicadores foram organizados em novas séries, gerando como resultado, o comportamento do risco (desvio padrão) e retorno (taxa geométrica de crescimento).

Após a obtenção das informações de risco e retorno, os mesmos foram plotados em pares ordenados (risco; retorno) para cada década em cada continente.

\section{RESULTADOS E DISCUSSÃO}

\section{Mercado internacional de papel}

Os valores da produção média para cada continente no período em estudo são apresentados na Tabela 1.

Tabela 1: Produção média de papel por continente entre as décadas de 1960 e 2000

\begin{tabular}{|c|c|c|c|c|c|}
\hline \multirow{2}{*}{ Local } & \multicolumn{5}{|c|}{ Década } \\
\hline & 1960 & 1970 & 1980 & 1990 & 2000 \\
\hline África & $625.352,0$ & $1.288 .701,7$ & $2.335 .604,4$ & $2.825 .282,1$ & $3.855 .244,3$ \\
\hline América & $51.118 .120,8$ & $70.097 .444,0$ & $88.070 .744,6$ & $113.729 .221,1$ & $116.242 .969,5$ \\
\hline Ásia & $12.543 .960,0$ & $23.456 .230,0$ & $41.066 .690,0$ & $77.727 .057,5$ & $132.123 .423,0$ \\
\hline Europa & $33.728 .770,0$ & $51.542 .800,0$ & $66.909 .390,0$ & $84.632 .405,5$ & $107.447 .902,6$ \\
\hline Oceania & $1.094 .320,0$ & $1.776 .420,0$ & $2.327 .200,0$ & $3.162 .400,0$ & $3.976 .500,0$ \\
\hline
\end{tabular}

Analisando o mercado mundial de papel, quanto à participação individual de cada continente em relação à produção de papel, observou-se (Figura 1) que o mesmo sofreu alterações ao longo do tempo.

A

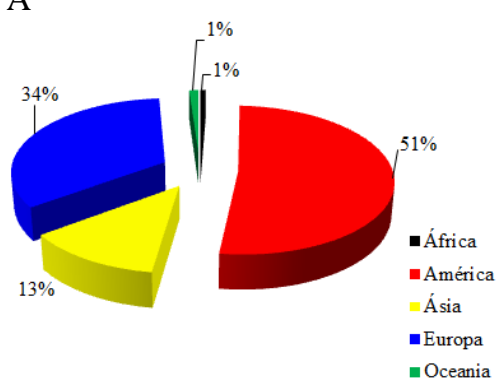

D

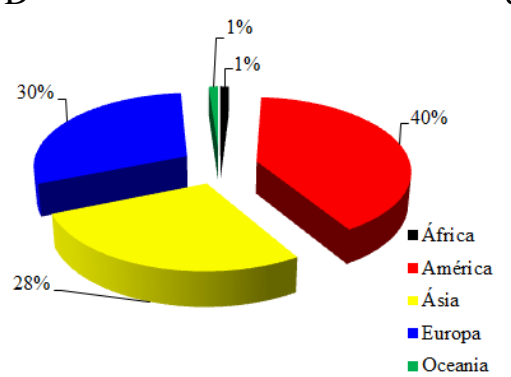

b

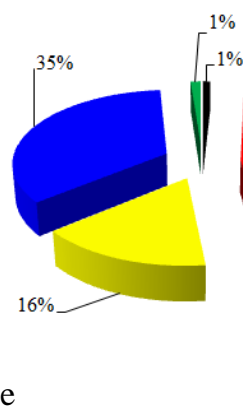

c

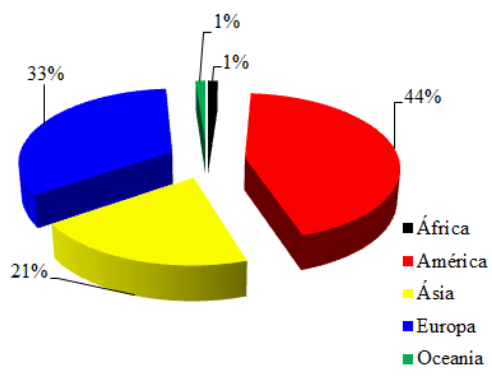

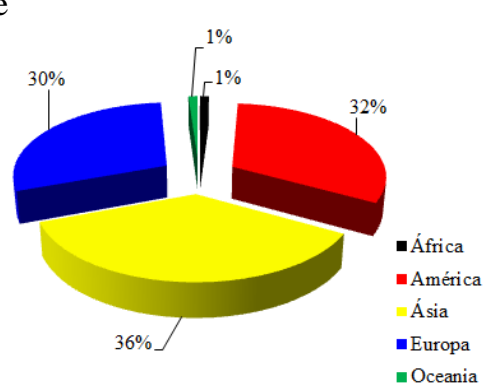

Figura 1: Evolução da produção mundial de papel por década, em que: $a$ = década de 1960; $b=$ década de 1970; c = década de 1980; $d$ = década de 1990 e e= década de 2000. 
A produção mundial de papel é caracterizada por diferenças em relação à participação de cada um dos mercados que o compõe. No período analisado (1961 a 2010) a produção ficou concentrada em dois continentes (América e Europa) os quais responderam por mais de 50\% do total produzido. Entretanto, verificou-se uma crescente participação da Ásia em todo o período, que na década de 1960 representava 13\% da produção mundial e na década de 2000 passou para $36 \%$.

Em relação às TGC's calculadas (Tabela 2), verifica-se que, com exceção do continente americano na década de 2000, ocorreram taxas positivas de TGC indicando que houve crescimento da produção de papel no período analisado.

Tabela 2. Taxas Geométricas de Crescimento (TGC) da produção de papel por continentes durante as décadas de 1960 e de 2000.

\begin{tabular}{llllll}
\hline \multirow{2}{*}{ Continente } & \multicolumn{5}{c}{ Década } \\
\cline { 2 - 6 } & $\mathbf{1 9 6 0}$ & $\mathbf{1 9 7 0}$ & $\mathbf{1 9 8 0}$ & $\mathbf{1 9 9 0}$ & $\mathbf{2 0 0 0}$ \\
\hline África & 11,21 & 6,41 & 4,75 & 2,56 & 0,33 \\
América & 5,02 & 2,18 & 3,27 & 2,39 & $-0,86$ \\
Ásia & 7,48 & 5,00 & 8,19 & 5,31 & 6,66 \\
Europa & 7,60 & 2,54 & 3,74 & 3,19 & 0,60 \\
Oceania & 8,04 & 3,21 & 2,62 & 3,07 & 1,77 \\
\hline
\end{tabular}

Na década de 1960 a produção de papel apresentou tendência crescente em todos os continentes apresentando coerência com o crescimento econômico que ocorreu no mundo no período pósguerra (1949-1973) [15].

A África e a Oceania apresentaram os maiores valores de TGC entre todos os continentes nesta década, com valores de 11,21 e $8,04 \%$, respectivamente. Porém, ressalta-se que, neste período, ambos os continentes participaram com apenas $1,7 \%$ da produção mundial.

Na década de 1970, verifica-se que as taxas apresentaram comportamento crescente, porém, o crescimento foi inferior ao observado na década anterior. Uma possível explicação para o decréscimo nas taxas de crescimento pode ser dada pela crise do petróleo que afetou todos os setores econômicos e que, em conjunto com a escassez da madeira, foi responsável por aumentar os preços de celulose em cerca de $588 \%$ [16].

Já na década de 1980, verifica-se que os mercados americano, asiático e europeu apresentaram taxas crescentes de produção enquanto que os mercados da África e Oceania continuaram apresentando taxas decrescentes quando comparados com a década anterior.

A década de 1990 foi representada por taxas decrescentes de produção em relação à década anterior. De acordo com Lopes et al. [17], o setor papeleiro passou por uma crise sem precedentes no período entre 1991 e 1993 em função da recessão mundial o que fez com que a produção de papel permanecesse estagnada.

Na década de 1990, a Oceania foi o único dentre os continentes a apresentar TGC superior à década anterior. Tal fato é devido ao aumento significativo que teve em sua produção de papea qual passou de 2.833.000 t em 1991 para 3.713.000 em 2010.

Embora tenha ocorrido recessões econômicas em vários países na década de 1990, a mesma foi caracterizada pela estabilidade política e pelo crescimento econômico dos E.U.A. e da Europa Ocidental, os quais, no período, eram responsáveis pelo consumo de quase dois terços do papel produzido no mundo e alavancaram a economia mundial ao longo da referida década [19].

A década de 2000 apresentou, com exceção da Ásia, TGC's decrescentes em relação à década anterior. Nesse período o apresentou TGC negativo mercado fato que não foi verificado para os mercados estudados entre as décadas de 1960 e 1990. Este comportamento é explicado pela crise do mercado imobiliário do E.U.A. no ano de 2007 que desencadeou uma crise financeira que alastrou para todo o mundo e provocou uma recessão económica generalizada [20].

De acordo com o Instituto Observatório Social [21], apesar dos países desenvolvidos apresentarem eficiência na produção de papel, também possuem dificuldades nas fases iniciais da cadeia produtiva, basicamente, na plantação de florestas homogêneas. Este fator pode ser uma das razões que explicam a relativa estagnação verificada no continente americano na década de 2000.

O mercado asiático merece uma análise a parte. A partir da década de 1980 demonstrou taxas de crescimento superiores ao restante do mundo. Mesmo na década de 1990, onde todos os mercados 
analisados tiveram decréscimos na TGC's, o mercado asiático continuou superior aos demais e no período subsequente foi o único a elevar as suas taxas de crescimento tornando-se neste período o maior produtor de papel e papelão do mundo. Além do fato do Japão, tradicional produtor de papel, continuar mantendo sua produção em alta, essa posição de destaque da Ásia no mercado internacional papeleiro está vinculada ao desenvolvimento de países não tradicionais e principalmente pela ascensão da China.

\section{Risco/retorno das importações e exportações de papel}

A Figura 2 apresenta a evolução dos níveis de risco e retorno das importações para cada continente ao longo das cinco décadas do período em análise.
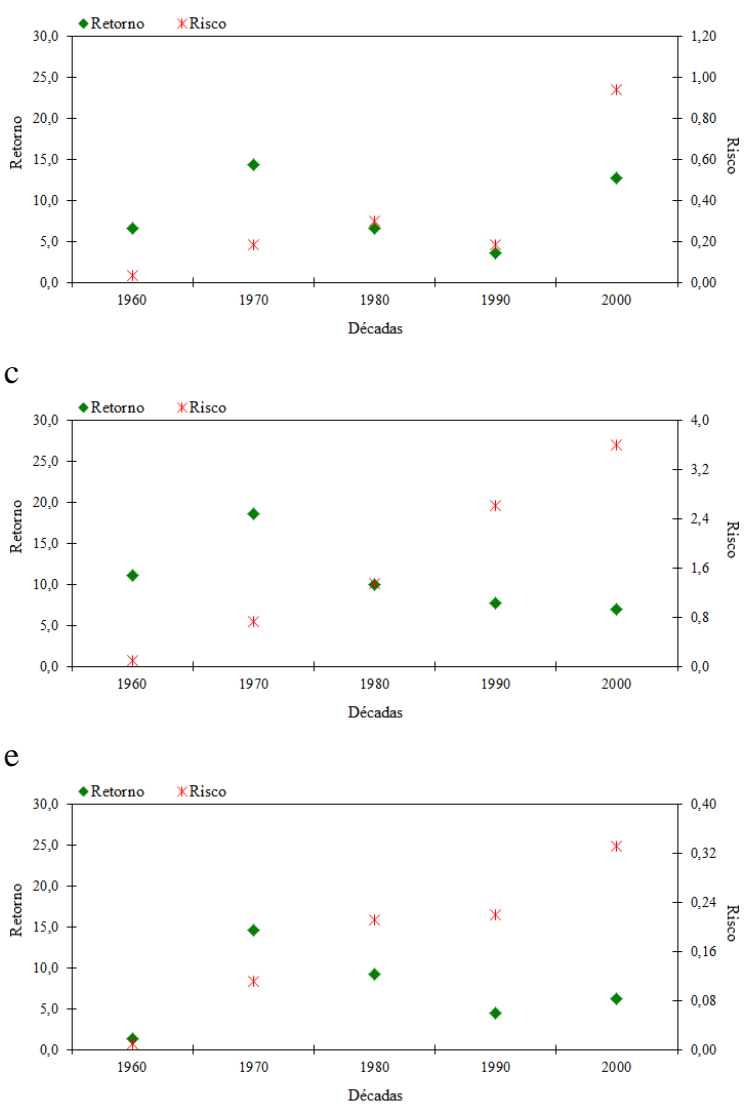

B

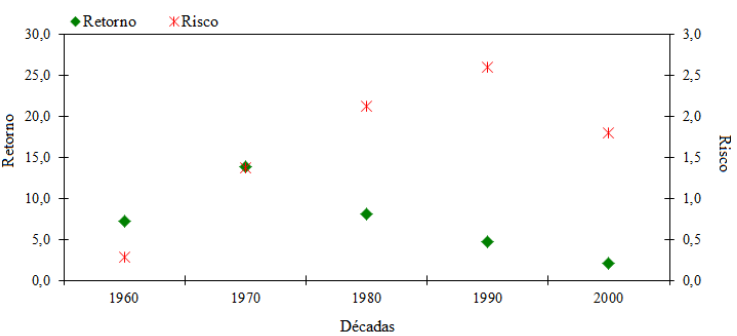

$\mathrm{D}$

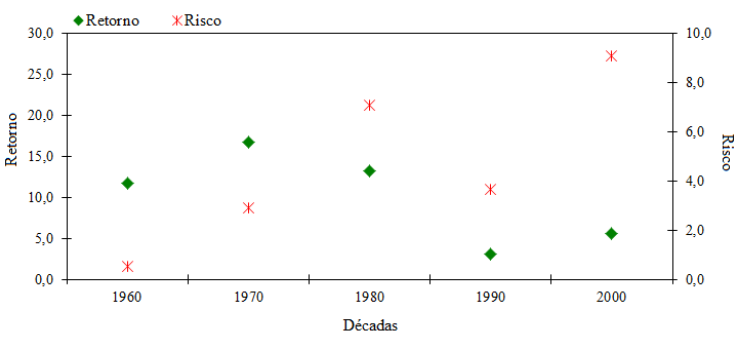

Figura 2. Evolução da relação risco/retorno para as importações de papel nas décadas de 1960, 1970, 1980, 1990 e 2000. Em que: $a=$ África; $b=$ América; $c=$ Ásia; $d=$ Europa e e = Oceania.

No período entre a década de 1960 e 1970 ocorreram relações positivas quanto a risco e retorno das importações. Neste período os retornos sempre superaram os riscos com relação simétrica em todos os mercados. Este comportamento favorável pode ser explicado pelo fato de que a economia mundial ingressava numa fase de expansão com o aumento do comércio e dos investimentos nas três décadas seguintes à $2^{\mathrm{a}}$ Guerra Mundial [22].

Entre as décadas de 1970 e 1980 ocorreu uma assimetria desfavorável (risco crescente e retorno decrescente) em todos os mercados. Este aumento do risco pode ser explicado pelas mudanças econômicas do período como a crise do petróleo e às sucessivas recessões de 1974-1975 e 19801982 que provocaram recessão e elevação da inflação nos principais países importadores de papel do primeiro mundo o que gerou instabilidade em vários setores da economia mundial.

Na década 1990 ocorreu o retorno da estabilidade nas importações na África, Europa e Oceania, enquanto que na América e Ásia os retornos continuaram decrescentes e os riscos crescentes. A situação do continente asiático pode ser explicada pela crise ocorrida no Japão (um dos maiores importadores de papel da Ásia) [23]. 
O mercado americano também apresentou uma alta variação nas importações, porém com valores de importação oscilantes e com taxas de crescimento sempre inferiores quando comparadas aos demais mercados.

A relação risco/retorno para as importações de papel apresentaram tendência simétrica durante a década de 2000, sendo crescente para África, Europa e Oceania, enquanto que na América essa relação decresceu. A Ásia apresentou, assim como na década anterior, retornos inferiores e riscos elevados.

Em relação às exportações da produção de papel, a evolução dos níveis de risco e retorno do mercado papeleiro em cada continente entre as décadas de 1960 e 2000 é apresentada na Figura 3.
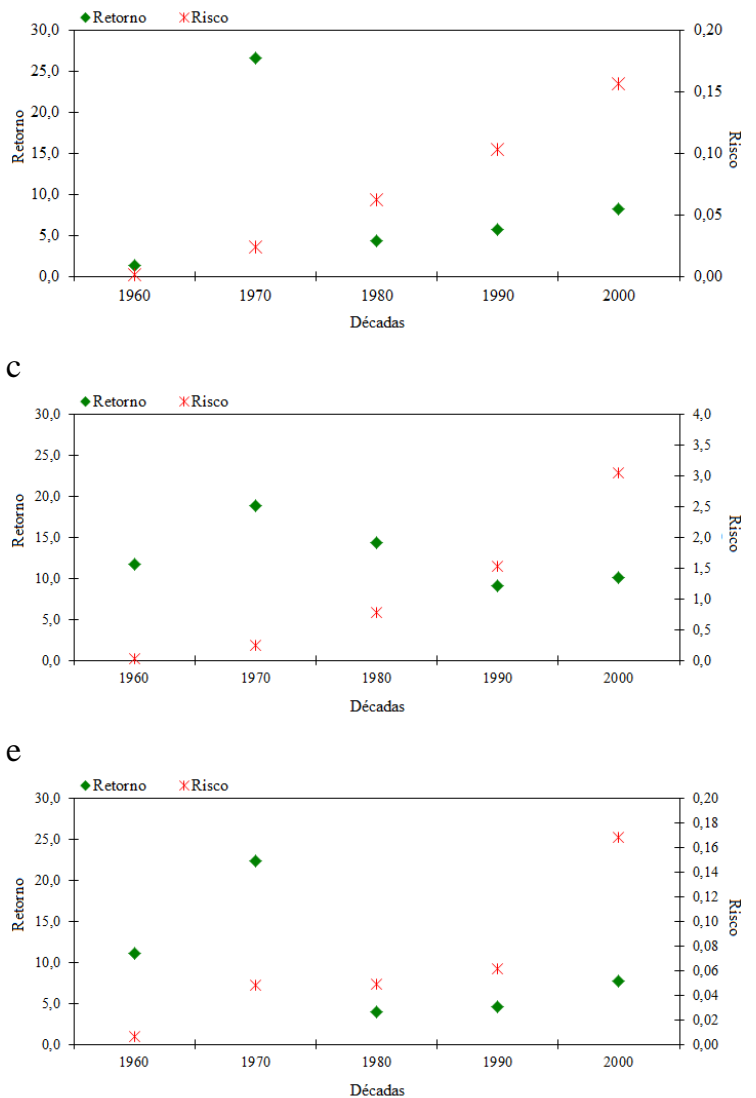

B

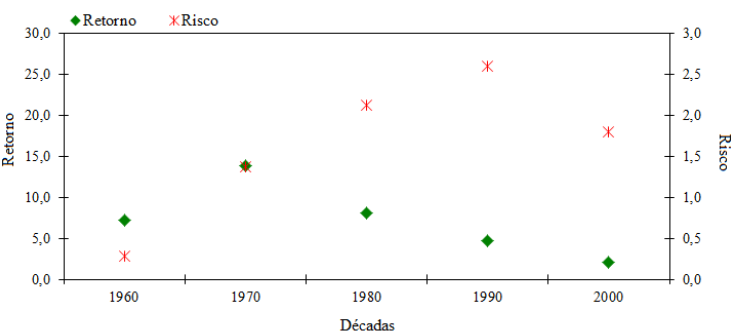

$\mathrm{D}$

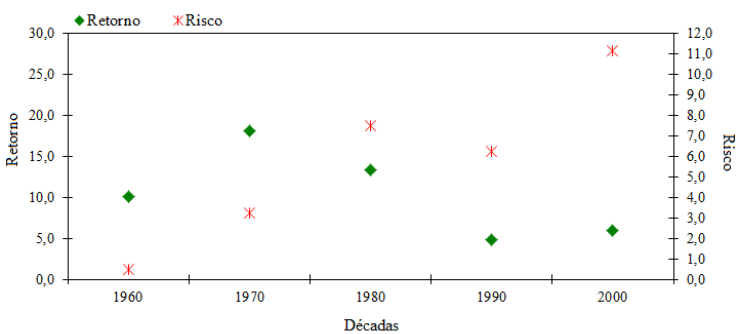

Figura 3. Evolução da relação risco/retorno para as exportações de papel nas décadas de 1960, 1970, 1980, 1990 e 2000. Em que: $a=$ África; $b=$ América; $c=$ Ásia; $d=$ Europa e e = Oceania .

Assim como as importações, as exportações de papel apresentaram uma relação risco/retorno positiva em todas as décadas analisadas. Na década de 1960 a Ásia apresentou retorno elevado e risco quase nulo.

A década de 1970 foi caracterizada por apresentar um aumento dos riscos e retornos das exportações em todos os mercados, porém com riscos menos acentuados do que os retornos.

A relação risco/retorno das exportações na década de 1980 apresentou o mesmo padrão de assimetria encontrado para as importações. Esse comportamento pode ser reflexo da crise petrolífera ocorrida no período e a recessão que dela resultou a qual afetou a economia africana até o final do século XX [25] e explica o decréscimo apresentado pelo retorno das exportações deste continente.

As relações risco/retorno na década de 1990 foram inferiores às observadas na década anterior com exceção da Oceania e África. Embora tenha apresentado retorno inferior ao da década anterior, a Ásia se destacou no período obtendo o retorno mais elevado entre os mercados avaliados.

O comportamento da relação risco/retorno no período entre 1980 e 1990 apresentou variação conforme o mercado analisado, sendo assimétrico, ou seja, desfavorável para os continentes americano e asiático e simétrico, ou seja, favorável, para os demais continentes. Um investimento 
atrativo ao capital privado é aquele que apresente, pelo menos, taxas de risco e retorno que cresçam e decresçam de forma simétrica [25]. Dessa forma, apenas os mercados americano e asiático apresentaram-se atrativos para investimentos no período.

A década de 2000 apresentou para todos os mercados analisados uma tendência crescente em relação ao período anterior. Porém, esta década foi caracterizada por apresentar riscos altíssimos e retornos baixos, principalmente no mercado americano que foi o mais afetado pela crise do mercado imobiliário dos E.U.A. [26].

Em todo o período analisado, verifico-se que o mercado internacional de papel não se caracterizou como um mercado engessado, pois respondeu negativa ou positivamente às variações macroeconômicas ocorridas no período analisado, apresentando taxas geométricas de crescimento variáveis em relação aos mercados concorrentes, assim como variações no próprio mercado ao longo do tempo.

\section{CONCLUSÃO}

Entre 1961 e 2010, a produção de papel ficou concentrada nos países dos continentes americano e europeu, caracterizando-se pela crescente produção da Ásia e decrescente produção da América.

As importações internacionais de papel apresentaram de uma forma geral, com exceção do mercado asiático, uma tendência simétrica para a relação risco-retorno, mostrando-se como um investimento atrativo.

A relação risco-retorno para as exportações mostrou-se similar as importações com tendências assimétricas entre 1970 e 1980 para todos os continentes, e entre 1980 e 1990 para o asiático e americano, e tendências simétricas para os demais períodos, apresentando riscos e retornos oscilando ao longo do tempo.

\section{REFERÊNCIAS BIBLIOGRÁFICAS}

1. Klock U, Andrade AS, Hernandes JA. Polpa e papel. 3 ed. Curitiba: UFPR; 2013. 117 p.

2. Macedo ARP, Valença ACV. A indústria de papel no Brasil e no mundo - uma visão geral. Rio de Janeiro: BNDES; 1995. 13 p.

3. Özarslan DD, Altay MC, Arabaci A, Altay HF, Sivri N. Effects of high economic importance of industrial branches on human life quality and environment. International Journal of Electronics, Mechanical and Mechatronics Engineering. 2011; 2(1): 86-91.

4. Souza DT. Demanda e intensidade do uso de materiais básicos em economias recentemente industrializadas. [tese]. São Carlos (SP): Universidade Federal de São Carlos; 2013. 188 p.

5. Ruonala-Lindgren A. Global paper consumption is growing. 2013. Disponível em: <http://www.forestindustries.fi/industry/paper_cardboard_converted/paper_pulp/Global-paper consumption-is-growing-1287.html> Acesso em: 25 out. 2014.

6. WBCSD - The World Business Council for Sustainable Development. A changing future for paper. New York: WPCSP; 1996. 32 p.

7. Oberling DF, La Rovere EL. Impactos socioambientais das cadeias produtivas: papel e celulose. Belo Horizonte: UFMG; 2010. 128 p.

8. FAO - Food and Agriculture Organization of the United Nations. ForesSTAT. 2014. Disponível em: <http://faostat.fao.org/site/626/default.aspx\#ancor> Acesso em: 15 jan. 2014.

9. Gujarati DN, Porter D. Econometria básica. 5 ed. Porto Alegre: ARTMED; 2011.924 p.

10. Noce R, Oliveira JM, Carvalho RMMA, Silva ML, Rezende JLP, Mendes LM, Barbosa TRCG. Análise de tendência do mercado internacional de aglomerado. Revista Árvore. 2008; 32(2): 245-250.

11. Soares NS, Silva ML, Valverde SR, Alves RR, Santos FL. Análise econométrica da demanda brasileira de importação de borracha natural, de 1964 a 2005. Revista Árvore. 2008; 32(6): 1133-1142.

12. Gouveia VM. O mercado de amêndoas de babaçu no estado do Maranhão. [tese]. Brasília (DF): Universidade de Brasília; 2015. 127 p.

13. Groppelli AA, Nikbakht E. Administração financeira. 3 ed. São Paulo: Saraiva, 2010. 496 p.

14. Gitman LJ. Princípios de administração financeira. 12 ed. São Paulo: Pearson Addison Wesley, 2010. $776 \mathrm{p}$.

15. McNally D. Da crise financeira a recessão mundial: acumulação financeirização e declínio global. Revistada Sociedade Brasileira de Economia Política. 2012; 32: 143-165. 
16. Cruz ES. Análise do comércio mundial de celulose e papel. [dissertação]. Lavras (MG): Universidade Federal de Lavras; 2001. 141 p.

17. Lopes AB, Reis ACF, Obukawa AO. A aplicação dos 4P's na indústria papeleira: o caso brasileiro. Caderno de Pesquisas em Administração. 1996; 1(2): 1-10.

18. Soto JH. Crise financeira e recessão. 2008. Disponível em: <http://www.mises.org.br/Article.aspx?id=178>. Acesso em: 31 out. 2014.

19. Valença ACV, Mattos RLG. A década de 90: mercado mundial de papeis. Rio de Janeiro: BNDES; 2000. $39 \mathrm{p}$.

20. Rolo JM. Os senhores da crise. Economia Global e Gestão. 2009; 14 (2): 65-80.

21. IOS - Instituto Observatório Social. Relatório geral: panorama econômico e sindical do setor de papel e celulose nos países do Cone Sul. São Paulo: [s.n.]. 2009. Disponível em: <http://www.observatoriosocial.org.br/site/sites/default/files/relatoriogeral_setordepapelecelulose_jul2 009.pdf>. Acesso em: 21 out. 2014.

22. Almeida PR. A economia internacional no século XX: um ensaio de síntese. Revista Brasileira de Politica Internacional. 2001; 44 (1): 112-136.

23. Bueno EU, Castelli JR. Crise de balance sheet, instabilidade política e expectativas: a crise global japonesa de 1991 e suas lições para o atual contexto de crise global. In: Anais do V Encontro Internacional da Associação Keynesiana Brasileira; 2012; São Paulo. São Paulo: Associação Keynesiana Brasileira; 2012. p.1-20.

24. Oliveira RS. A África desde o fim da Guerra Fria. Relações Internacionais. 2009; 24: 93-114.

25. Mota JH, Noce R, Yuri JE, Resende GM, Souza RJ. Análise da evolução da produção e relação risco e retorno para a cultura do alho, no Brasil e regiões (1991 a 2000). Horticultura Brasileira. 2005; 23 (2): 238-241.

26. Cintra MAC, Farhi M. A crise financeira e o Global Shadow Banking System. Novos estudos- CEBRAP. 2008; 82: 35-55. 